\title{
Role of Cortical Mastoidectomy in the Management of Mucosal Chronic Suppurative Otitis Media
}

\author{
Sumit Sharma ${ }^{1}$, Chhavi Gupta ${ }^{2}$, Richa Singh $^{3}$, Suvarna Sharma ${ }^{4}$ \\ ${ }^{1}$ Associate Professor, ${ }^{2}$ Assistant Professor, ${ }^{3}$ Audiologist; \\ Department of E.N.T., Mayo Institute of Medical Sciences, Barabanki, U.P., India; \\ ${ }^{4}$ MBBS $4{ }^{\text {th }}$ Year Students, KMC Manipal. \\ Corresponding Author: Chhavi Gupta
}

\begin{abstract}
This is a comparative study done to evaluate outcome of type 1 Tympanoplasty with and without mastoidectomy in terms of hearing improvement and graft uptake. This is a prospective study done in 100 patients at a tertiary care referral centre during November 2018 to march 2020. Patients were divided in two groups, Group A consists of 50 patients in whom type 1 Tympanoplasty was done and in Group B 50 patients were there who had undergone Type 1 Tympanoplasty with cortical mastoidectomy. Patients were evaluated postoperatively at $2^{\text {nd }} \mathrm{wk}, 4^{\text {th }} \mathrm{wk}, 2^{\text {nd }}$ month and $3^{\text {rd }}$ month for graft uptake, disease clearance, and hearing improvement. PTA was done at $3^{\text {rd }}$ month postoperatively. In our study we observed graft uptake in $94 \%$ of patients in Group A as compared to $98 \%$ of patients in Group B and in terms of hearing improvement there is not much difference in both the groups i.e. in Group A it is $13.996 \pm 4.235$ while in Group B it is $14.172 \pm 5.381 \mathrm{P}$ value is 1 which means there is no statistically significant difference in two groups. Though better results were observed for cortical mastoidectomy with Type 1 Tympanoplasty than Type 1 Tympanoplasty alone but the difference was insignificant.
\end{abstract}

Keywords: Cortical Mastoidectomy; Mucosal Chronic Suppurative Otitis Media; CSOM

\section{INTRODUCTION}

Chronic suppurative otitis media (CSOM) remains one of the most common chronic infectious diseases worldwide.
Although microbial, immunological, and genetically determined factors, as well as eustachian tube (ET) dysfunction, are supposed to be involved in the pathogenesis of CSOM, many aspects of the pathogenesis still need to be clarified ${ }^{(1)}$

The term Tympanoplasty was first used in 1953 by Wullstein (2) to describe surgical techniques for reconstruction of middle ear hearing mechanisms that had been destroyed by chronic ear disease. A number of histopathological changes can develop in the middle ear and mastoid in chronic suppurative otitis media determining the success or failure of tympanomastoid surgery. Tympanoplasty is a commonly performed surgical procedure to close perforations of the tympanic membrane; the results of tympanic membrane repair, although generally favorable, can vary significantly based on multiple factors, including infection, ET dysfunction, and variations in the operative technique. The contribution of mastoid pneumatization remains controversial, and the role of mastoidectomy in treating tympanic membrane perforations continues to be debated, particularly in the cases of chronic suppurative otitis media in the absence of cholesteatoma. ${ }^{(3)}$

Perforation of the tympanic membrane is nature's way of maintaining middle ear ventilation under the pressure of inflammatory process in the middle ear cleft. The two opposing demands of tympanoplasty namely, removal of all 

media.

disease process and at the same time trying to maintain as much of normal tissue as possible to facilitate reconstruction of the hearing mechanism is a demanding task. As long as there is infection lurking in and around the middle ear cleft and mastoid antrum, any attempt at reconstruction may seem futile. In this context cortical mastoidectomy seems to be an integral part of every tympanoplasty. An attempt is made in this study to analyze the role of cortical mastoidectomy in the surgical outcome of tympanoplasty. ${ }^{(4)}$

\section{Aims \& Objectives:}

The aim of this study is to assess the effect of cortical mastoidectomy on treatment of mucosal chronic suppurative otitis media; we performed a comparison of patients with tympanic membrane perforations treated with tympanoplasty or with tympanoplasty combined with cortical mastoidectomy with respect to hearing improvement and graft uptake after 3 months duration.

\section{MATERIAL \& METHODS}

This is a prospective study carried out on 100 patients who attended the outpatient clinic of Otorhinolaryngology Department, Mayo Institute of Medical Sciences, Barabanki. Patients were randomly divided into two equal groups; Group A included 50 patients who underwent Tympanoplasty alone, whereas Group B included 50 patients who underwent Tympanoplasty with cortical mastoidectomy.

Informed consent had been taken from every patient with explanation of the aim of the study.

Study Period: from; November 2018 to March 2020 and met the Inclusion criteria's were taken into the study.

They were divided into two groups

Group A $(\mathbf{n}=\mathbf{5 0})$ : All the patients suffering from Tubotympanic type of Chronic Suppurative Otitis Media underwent Tympanoplasty without Cortical Mastoidectomy
Group B $(\mathbf{n = 5 0 ) : ~ A l l ~ t h e ~ p a t i e n t s ~ s u f f e r i n g ~}$ from Tubotympanic type of Chronic Suppurative Otitis Media underwent Tympanoplasty with Cortical Mastoidectomy.

\section{Inclusion criteria:}

1. Tubotympanic type of CSOM

2. Dry ear for the past 3 weeks

3. Conductive type hearing loss

\section{Exclusion criteria:}

1. Atticoantral type of CSOM

2. Sensorineural or mixed hearing loss

3. Age below 14 years and above 65 years

4. Previous mastoid surgery

Pre-operative evaluation included a detailed history of the patient, examination both -general and local, along with EUM, tuning fork tests with 256,512 and $1024 \mathrm{~Hz}$ for the degree of hearing loss, and Pure Tone Audiometry for documentation. Routine radiological evaluation for Tubotympanic type of CSOM is not done. Routine blood investigations included complete blood count, bleeding and clotting time, kidney function test, liver function test, and random blood sugar examination and viral markers. They were then subjected to routine preanesthetic checkup. Depending on the intervention, all the patients were then subjected to Surgery as per the two groups. Classical underlay tympanoplasty was done in all the cases. All the preoperative and per operative findings were documented and evaluated statistically. Surgery was done under General Anaesthesia.

Post operative evaluation was done after 2 weeks, 4 weeks and 2 months and 3 months in evaluation following points was observed:

1. Graft Uptake

2. Residual perforation / Retraction / Lateralization

3. Audiological improvement

4. Tympanogram results 
Sumit Sharma et.al. Role of cortical mastoidectomy in the management of mucosal chronic suppurative otitis media.

\section{OBSERVATIONS}

In the present study a total of 100 patients who met the Inclusion criteria were divided in Group A and Group B 50 patients each, Group A patients were undergone Type 1 Tympanoplasty and Group B patients were undergone cortical mastoidectomy with Type 1 Tympanoplasty. The present study was conducted from November 2018 to march
2020, in the Department of E.N.T at Mayo Institute of Medical Sciences, Barabanki.

Table 1: Age wise distribution of patients between 15-55years
\begin{tabular}{|l|l|l|}
\hline Age & Group A & Group B \\
\hline $15-24$ & $13(26 \%)$ & $10(20 \%)$ \\
\hline $25-34$ & $22(44 \%)$ & $21(42 \%)$ \\
\hline $35-44$ & $11(22 \%)$ & $13(26 \%)$ \\
\hline $45-55$ & $4(8 \%)$ & $6(12 \%)$ \\
\hline
\end{tabular}

Patients in our study were taken from 15-55year age group; most common age group is 25 to 34 year in both groups.

Table 2: Sex distribution / Ear Involved by the disease in patients between 15-55years

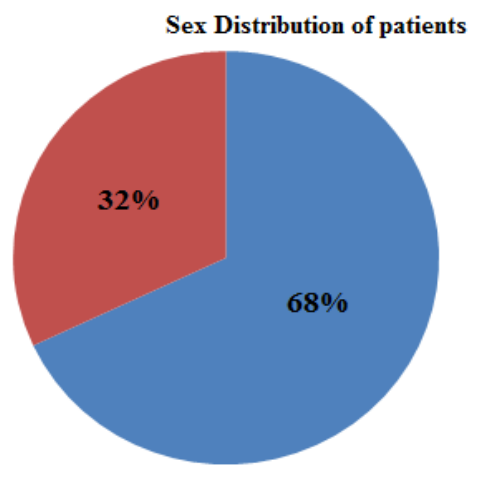

In the present study $68 \%$ patients were females and $32 \%$ were males. Right ear is more commonly involved $(62 \%)$ as compared to left ear which (38\%.)

Table 3: Duration of Ear Discharge
\begin{tabular}{|l|l|l|l|l|}
\hline & GROUP A & $\%$ & GROUP B & $\%$ \\
\hline$<1$ Year & 7 & $14 \%$ & 5 & $10 \%$ \\
\hline 1-5 Year & 17 & $34 \%$ & 21 & $42 \%$ \\
\hline 5-10 Year & 18 & $36 \%$ & 14 & $28 \%$ \\
\hline$>10$ Year & 8 & $16 \%$ & 10 & $20 \%$ \\
\hline
\end{tabular}

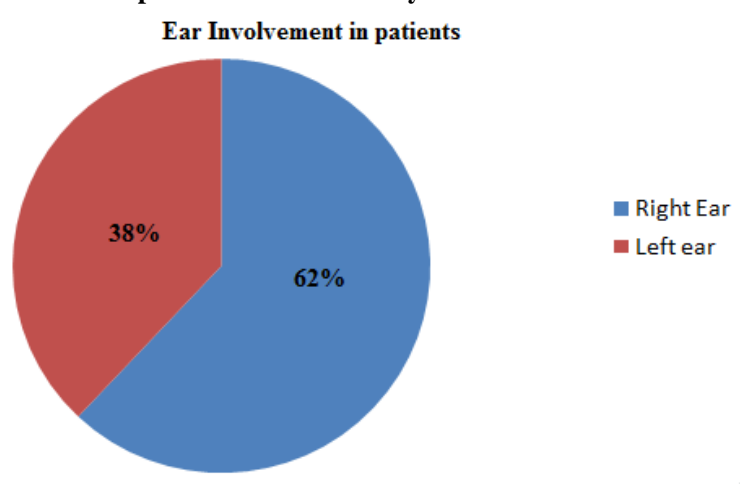

Majority of patients in Group A had ear discharge for 5-10 years (36\%) followed by $34 \%$ in $1-5$ years of age, only $16 \%$ had ear discharge of more than 10 years and $14 \%$ had ear discharge of less than 1 year; whereas in Group B majority of the patients $(42 \%)$ had ear discharge for 1-5 years followed by $28 \%$ had it for $5-10$ years; $20 \%$ had it for more than 10 years and $10 \%$ had it for less than 1 year.

Table 4: Size of Perforation and Graft Uptake after 3 Months

\begin{tabular}{|c|c|c|c|c|c|}
\hline \multicolumn{3}{|c|}{ Size Of Perforation } & \multicolumn{3}{|c|}{ Graft Uptake after 3 Months } \\
\hline & GROUP A & GROUP B & & GROUP A & GROUP B \\
\hline Small & $4(8 \%)$ & $5(10 \%)$ & \multirow[t]{2}{*}{ Graft Uptake } & \multirow[t]{2}{*}{$47(94 \%)$} & \multirow[t]{2}{*}{$49(98 \%)$} \\
\hline Medium & $12(24 \%)$ & $17(34 \%)$ & & & \\
\hline Large & $26(52 \%)$ & $20(40 \%)$ & \multirow[t]{2}{*}{ Residual Perforation } & \multirow[t]{2}{*}{$3(65)$} & \multirow[t]{2}{*}{$1(2 \%)$} \\
\hline Sub Total & $8(16 \%)$ & $8(16 \%)$ & & & \\
\hline
\end{tabular}

Large central perforation is most common in both the groups. In group A; after 3 months graft uptake was observed in $94 \%$ of patents where as in group B $98 \%$ of graft uptake was observed.

Table 5: Audiological Assessment

\begin{tabular}{|l|l|l|l|l|l|}
\hline \multicolumn{1}{|c|}{ Preoperative Audiological Assessment } & \multicolumn{3}{l|}{ Postoperative Audiological Assessment } \\
\hline & GROUP A & GROUP B & & GROUP A & GROUP B \\
\hline Pre Op AB Gap & $27.21 \pm 6.93$ & $28.25 \pm 7.59$ & Post OP AB Gap & $12.81 \pm 6.78$ & $14.87 \pm 7.59$ \\
\hline Pre Op Ac Threshold & $33.97 \pm 7.60$ & $33.63 \pm 7.18$ & Post OP AC Threshold & $19.97 \pm 6.79$ & $18.94 \pm 7.18$ \\
\hline
\end{tabular}

Preoperative AB gap in group $\mathrm{A}$ is $27.21 \pm 6.93$ while in Group B is $28.25 \pm$ 7.59 and post operative AB gap in Group A is $12.81 \pm 6.78$ and in Group $\mathrm{B}$ is $14.87 \pm$ 7.59 so $\mathrm{AB}$ gain in Group $\mathrm{A}$ is 14.452 and in Group $B$ is $13.274, \mathrm{P}$ value of $\mathrm{AB}$ gain 

media.

for both groups comes to be 0.229206797 which is $>.05$ that means difference in $\mathrm{AB}$ gain for both the groups is insignificant.

Table 6: Assessment of Audiological Improvement

\begin{tabular}{|l|l|l|}
\hline Audiological Finding & GROUP A & GROUP B \\
\hline Before(Ac Threshold) & $33.97 \pm 7.60$ & $33.63 \pm 7.18$ \\
\hline After(Ac Threshold) & $19.97 \pm 6.79$ & $18.94 \pm 7.18$ \\
\hline Benefit & $13.996 \pm 4.235$ & $14.172 \pm 5.381$ \\
\hline
\end{tabular}

Hearing improvement in Group A is $13.996 \pm 4.235$, while hearing improvement in Group B is $14.172 \pm 5.381$, difference of audiological gain in both the groups is found to be statistically insignificant as $\mathrm{P}$ value is 1 which is $>0.05$.

\section{DISCUSSION}

Mastoidectomy is one of the most common Otological operations performed today. Indications for mastoidectomy range from eradication of chronic infection to approaches for various neurological procedures. Owing to not able to achieve $100 \%$ results in Tympanoplasty tempted a number of ENT specialist to do cortical mastoidectomy considering that it might improve results. Over the years two groups have developed; one think that mastoidectomy can allow surgical debridement of infected and devitalized tissues that can lead to persistent middle-ear disease, Others argue that performing mastoidectomy in these patients is unnecessary, does not improve the surgical outcome, and patients to increased surgical risks. To solve this dilemma we undertook this study to establish the role of Cortical Mastoidectomy in the management of mucosal Chronic Suppurative Otitis Media.

The sample size is comparable to the studies of Rama Krishna et al, Habib et al and Bhat et al whose sample size was 62, 60 and 68 respectively. The follow-up period was 3 months which was similar to studies conducted by Ramakrishna et al and Habib et al. ${ }^{(5)}$

In the study conducted by Aggarwal $\mathrm{D}{ }^{(5)}$ maximum number of patients in both the groups were distributed between the ages 20-30 years (22 patients). This was followed by patients in the age group 31-40 years (16 patients). Patients in the age group less than $20 \mathrm{yrs}$ were 9 . The least number of patients were found to be in the 41-50 age group (6 patients). Patients in our study were taken from 15-55year age group; most common age group is 25 to 34 year in both groups. In their study, $58.3 \%$ were females and $41.6 \%$ were males whereas in the present study $68 \%$ patients were females and $32 \%$ were males suggesting disease to be more predominant in females. Right ear is most commonly involved (62\%) as compared left ear (38\%.) in our series.

In the study conducted by Mohanty $S^{(6)}$ the type of perforation was classified into central and subtotal. 8 (32\%) of the patients in the tympanoplasty group and 10 $(40 \%)$ in the cortical mastoidectomy group had subtotal perforation whereas in the study conducted by Aggarwal D ${ }^{(5)}$; his both the groups were comparable in terms of size of perforation $(\mathrm{p}=0.556)$. There were a total of 6 patients with small perforation, 35 with medium perforation, 13 with large perforation and 6 with sub-total perforation in the whole study population, whereas in our series Large central perforation was the most common in both the groups (52\% in Group a and $40 \%$ in Group B).

In the study conducted by Aggarwal $\mathrm{D}^{(5)}$; the overall graft uptake rate in our study was $88.33 \%$. The graft uptake rate in tympanoplasty group was $87 \%$ and $90 \%$ in the tympanoplasty with cortical mastoidectomy group. There was no significant difference in the graft uptake rates of the two groups. In the study done by Madayambath Sagesh ${ }^{(7)}$ they obtained a graft uptake rate of $91.3 \%$ in patients who had tympanoplasty alone and $93 \%$ in patients who had tympanoplasty with cortical mastoidectomy. They concluded that tympanoplasty combined with intact canal wall mastoidectomy offered no significant improvement over tympanoplasty alone, in the rate of closure of tympanic membrane perforations, excluding the cases with reservoir of infection. Kadaha SMS ${ }^{(3)}$ also observes similar findings and concluded that 
intergroup comparisons did not reveal any significant differences between the two methods after 3 and 6 months postoperatively $(\mathrm{P}<0.05)$. In group $\mathrm{A}$; after 3 months graft uptake was observed in $94 \%$ of patents where as in group B $98 \%$ of graft uptake was observed.

In the study conducted by Madayambath Sagesh (7) The hearing improvement that he obtained in terms of air-bone gap closure $\geq 10 \mathrm{~dB}$, were $78.1 \%$ in the tympanoplasty group and $81 \%$ in the mastoidectomy group, with the average closure being $15.1 \mathrm{~dB}$ and $15.3 \mathrm{~dB}$, respectively. In their study, McGrew et al. ${ }^{(8)}$ got an average air-bone gap closure of $17.6 \mathrm{~dB}$ in the tympanoplasty group and $11.4 \mathrm{~dB}$ in the mastoidectomy group, but with no significant difference between the two on statistical analysis. In the study by Mishiro $\mathrm{Y}$ et al., ${ }^{(9)}$ the rates of the postoperative air-bone gap within $20 \mathrm{~dB}$ were $81.6 \%$ in the first group and $90.4 \%$ in the latter, without a statistically significant difference. Tawab H.M.A ${ }^{(10)}$ etal also emphasized the fact that overall satisfactory hearing outcome with adequate air-bone closure can be achieved irrespective of cortical mastoidectomy. They found that AB gap in decibel in group 1 was $22.3 \pm 8.2$ preoperative and $18.3 \pm 10.0$ postoperative with $-4.0 \pm 9.8$ difference, while it was 22.5 \pm 8.5 preoperative in group 2 and $20.0 \pm 8.3$ postoperative with $-2.5 \pm 6.8$ difference. Balyan et al ${ }^{(11)}$ in 1997 also did a retrospective study of 323 patients to evaluate the role of mastoidectomy in noncholesteatomatous CSOM. They observed no statistically significant difference in hearing outcome when mastoidectomy was done. In our study also Preoperative AB gap in group A is $27.21 \pm 6.93$ while in Group B is $28.25 \pm 7.59$ and post operative $\mathrm{AB}$ gap in Group A is $12.81 \pm 6.78$ and in Group B is $14.87 \pm 7.59$ so $\mathrm{AB}$ gain in Group $\mathrm{A}$ is 14.452 and in Group B is 13.274 so $\mathrm{P}$ value of $\mathrm{AB}$ gain for both groups comes to be 0.229206797 which is $>.05$ that means difference in $\mathrm{AB}$ gain for both the groups is insignificant.

\section{CONCLUSION}

Some surgeons prefer to do cortical mastoidectomy with tympanoplasty in cases of mucosal chronic otitis media in an attempt to improve results. Tympanoplasties with and without cortical mastoidectomy in cases of chronic suppurative otitis media (mucosal type) showed no significant difference in graft take-up rates which are similar with or without mastoidectomy in our study. The addition of cortical mastoidectomy to type I tympanoplasty did not improve the hearing improvement in cases of chronic suppurative otitis media Tubotympanic disease also. Thus we conclude, cortical mastoidectomy is not necessary in cases of uncomplicated tympanoplasties.

\section{Ethical Considerations of the Study:}

1. Ethics Committee Approval: Ethics committee approval was received for this study from the Institutional Ethics Committee

2. Written Informed Consent was obtained from concerned subjects and authority of institutions.

3. Privacy, confidentiality and anonymity were granted.

4. Scientific objectivity was maintained with honesty and impartiality.

Authors' Contributions: Concept - S.S., CG; Design - S.S., CG; Supervision - S.S., CG; Resource - S.S., CG, RS; Materials S.S., CG; Data Collection and/or Processing - S.S., CG; Analysis and/or Interpretation S.S., CG; Literature Search - S.S., CG; Writing - S.S., CG; Critical Reviews - S.S., CG.

Conflict of Interest: The authors declare that this study has had no conflicts of interest.

Financial Disclosure: The authors declare that this study had received no financial support.

Acknowledgement: None 


\section{REFERENCES}

1. Verhoeff M, van der Veen EL, Rovers MM, Sanders EAM, Schilder AGM. 2015 Chronic suppurative otitis media: a review Int J PediatrOtorhinolaryngol 2006; 70:112.

2. Wullstein H. (Technic and early results of tympanoplasty Monatsschr Ohrenheilkcl Laryngorhinol. 1953:87:308-11.

3. Kadaha SMS, Mokhemara S M, Ibrahimb H A, Ibrahima H E- Impact of mastoidectomy on tympanoplasty for recurrent suppurative otitis media - The Egyptian Journal of Otolaryngology | Published by Wolters Kluwer - Medknow DOI: 10.4103/ejo.ejo_34_18

4. Krishnan A Reddy, E. K. , Chandrakiran C., Nalinesha K. M., Jagannath P. M. -Tympanoplasty With And Without Cortical Mastoidectomy - A Comparative Study -Indian Journal of Otolaryngology and Head and Neck Surge Vol. 54 No. 3, July September 2002

5. Aggarwal D, Vemu S, Kapur S. Tympanoplasty with and without cortical mastoidectomy in treatment of inactive mucosal chronic otitis media. Int $\mathbf{J}$ Otorhinolaryngol Head Neck Surg 2019; 5: xxx-xx.

6. Mohanty S, Devipriya V, Sreenivas C, Raj V. Comparison of Surgical Outcomes in Chronic Otitis Media (Mucosal) following Type 1 Tympanoplasty with and without Cortical Mastoidectomy -- International
Journal of Contemporary Medical Research -- Volume 3 | Issue 8 | August 2016

7. Sagesh M. Evaluation of outcomes of tympanoplasties with and without cortical mastoidectomy. Indian J Otol 2014;20 :17882.

8. McGrew BM, Jackson CG, Glasscock ME 3rd. Impact of mastoidectomy on simple tympanic membrane perforation repair. Laryngoscope 2004;114:506-11

9. Balyan FR, Celikkanat S, Aslan A, Taibah A, Russo A, Sanna M. Mastoidectomy in noncholesteatomatous chronic suppurative otitis media: Is it necessary? Otolaryngol Head Neck Surg 1997;117:592-5.

10. Tawab HMA, Gharib FM, Tareq M. Algarf and Louay S. ElSharkawy - Myringoplasty with and without Cortical Mastoidectomy in Treatment of Non-cholesteatomatous Chronic Otitis Media: A Comparative Study -- Clinical Medicine Insights: Ear, Nose and Throat 2014:7

11. Balyan FR, Celikkanat S, Aslan A, Taibah A, Russo A, Sanna M. Mastoidectomy in non cholesteatomatous chronic suppurative otitis media: is it necessary? Otolaryngol Head Neck Surg. 1997;117:592-595

How to cite this article: Sharma S, Gupta C, Singh R et.al. Role of cortical mastoidectomy in the management of mucosal chronic suppurative otitis media. International Journal of Research and Review. 2021; 8(7): 136-141. DOI: https://doi.org/10.52403/ijrr.20210718 